\title{
Thinking spaces of writing and engagement
}

\author{
J. J. Fall \\ Département de géographie et environnement, Université de Genève, Geneva, Switzerland
}

Correspondence to: J. J. Fall (juliet.fall@unige.ch)

Received: 22 April 2013 - Accepted: 9 May 2013 - Published: 30 May 2013

The task of a discussant is a thankless and difficult one: at worst a mere interlude for those wishing to ask questions, or get at the coffee, at best a thoughtful engagement that links disconnected threads and brings new insight. But how do we discuss three very creative, but different contributions, remaining true to their intentions yet providing gentle food for thought? I will follow Gunnar Olsson, who spoke at the symposium but is not published in this special issue, in suggesting that humour, and lack of zealotry, might be one possible avenue to head down. After all, there is no point in our work if we cannot enjoy it, and laugh, both at the absurdity of the world and at our own limitations in engaging with it. For rather uniquely, this symposium brought together a group of people who all rather like each other and share a level of personal and professional trust that makes engagement a real pleasure: united and brought together through their multilingual, multi-sited geographical paths outside and beyond the usual core. Amongst the stimulating discussions, we also had fun, we laughed, we groaned, we listened. This alone suggests that the future options of a newly vibrant journal are exciting, notwithstanding its ambitions of broadly extending the welcome to others beyond its historical beating-grounds. In this brief discussion, I will try to bring out some elements that these papers share, while pointing out what different emphases, with episodes from the past and present of the discipline, might mean for the future of the debates that will appear in this journal.

The three interventions I am discussing here by Claudio Minca, Ulf Strohmayer and Christian Abrahamsson each focus, at times agonizingly, on the pains of translations, on the difficulties of debate, on the trouble of language, and on how such struggles turn into and feed into a discipline called geography. Dare I suggest that this constant destabilizing, this intimate doubt about words and meanings can also be enjoyable? If our words wobble beneath us and make us lose our footing now and then, then surely zealotry is less likely to strike? If our tools need constant rethinking, can this not also be a source of bemusement and enjoyment? It is for me, but then this is perhaps no more than the perpetuation of postcolonial inequalities: the joint unearned double privilege of British parents and a Swiss education. But I cannot help thinking that it is stimulating to move between academic spaces and lose our certainties, it is productive to doubt, it is enjoyable - though at times inevitably tiring - to be constantly wondering what language to speak, for those lucky enough to be able to use several. And this event, let it be widely known, was also something of a closet gathering of cosmopolitan polyglots, sharing similar convoluted personal careers across national spaces and languages. When academic hybrids meet, they do joyously recognise in each other shared confusions and similarly negotiated jumbled habits. Many of us have used such strategic positioning to be heard in the spaces we also identify and criticise as hegemonic: just as this journal is using its own marginality to reclaim a central space of debate. The meeting was held in a country gloriously multiple yet at times terrifying rigid, that in its best moments likes to think of itself as an alternative space for new engagements. Switzerland certainly did offer a refuge to geographers fleeing their own academic zealots in times past, and largely continues to do so, as the foreign participants in Fribourg employed in local universities illustrated.

The question of language is central to these three papers, and for these three authors. Minca, Strohmayer and Abrahamsson invite us, in their own ways, to think about what we read, how we write and how we are read. They invite us to dwell on how our understanding relies on language, on shared language, on historical meaning embedded in words and founding tales. Each is revisiting and reinventing the past to rethink the future - or rather invoking a particular past, be it of the origins and genealogies of specific concepts, specific disciplinary episodes and debates or modes and pressures on publishing results. How do they do this? How do 
they creatively destabilize the certainties and open up avenues for new thought? They give varying space to this projection into the future: Abrahamsson hints at it scantly at the outset; Strohmayer explores (by looking backwards) whether we should either cling to the familiar and rest comfortably lodged within whichever "house" we happen to grow up in or instead engage in arduous and complex acts of translation between different traditions; while Minca is firmly grounded in the present, worrying about the direction the discipline is taking in terms of normalising publishing structures.

Minca mentions that we can no longer agree on what is the shared heritage of geography - who the "great past geographers" are, a point also made by Ola Söderström in his welcoming words in Fribourg. Abrahamsson takes a different tack: he tells us instead that we do need to read these past thinkers, but understand them not as universal figures but as individuals rooted in specific debates. Strategically, he positions himself as an insider, able to provide such context. Stohmayer and Abrahamsson are both convinced that specific histories are worth (re)telling, that the key moments they consider - the tales of space cadets and early political geographers - are crucial to making sense of what geography has become today. These are the glamorous, heroic and charismatic geographers who, we are told, built the discipline. Despite their obvious skill in retelling such tales and adding new insights, there is a je-ne-sais-quoi of déjà vu in these stories. Are we really building new debates by revisiting and obsessing about the usual suspects, the Big Men who were so skilful in ensuring their place in history? I suspect instead that it is in the marginal spaces of these tales that the interesting tidbits lie: in the missing conversations, in the misunderstandings and failed translations - those Chinese whispers Abrahamsson hints at but doesn't develop - rather than in the actual heroism of past cosmopolitan men. Yet branding is often everything in such tales, and we can think today of other specific academic cliques who do as much to spread the legend of their genesis as their own take on geographical theory.

Following on from Minca, Strohmayer makes us think further about moving beyond taken-for-granted national territories. He invites us to reflect specifically on the design of institutional structures, and the role these play in knowledge production and dispersion. Tracing the appearance and translations of the concept of "event", he shows through a particular case study how the innovative geographical practices associated with the 1960s might hold a key to understanding how intellectual traditions become shared traditions. If this conference provided a sort of group outing for polyglots, obsessing together about our own convoluted hybridity, selfstudy was brought to amusing heights in Strohmayer's intervention. Gunnar Olsson, who attended and spoke at the conference in Fribourg, was one of the original space cadets, thus both object and audience at this event. Strohmayer suggests that the 1960s were a unique time, specifically because one particular strand of geography was so closely associated with one group of key people. If these allegiances create useful networks of practice, and friends and colleagues to engage with, it must also be hard to shake off the sense of a need for faithful allegiance. Identities, even academic ones, are in any case more fluid than retellings often suggest. Space cadets end up needing hearing aids, and the 1960s are remembered not so much for free love as for rigid mathematics. Familiar spaces are collapsed as networks of exchanges, personal encounters and times are redrawn.

Behind these attempts to think about shared origins and unity rests the long-standing idea of an "international" geography, a uniquely shared disciplinary space for geography, a global shared debate. But have we ever really discussed, in all the many recent editorials and papers about knowledge production that Minca revisits, whether we really want or indeed need one international geography? Isn't the diversity, helped by bridges and go-betweens, rather fun too? Minca addresses this question in saying that the question of language, and the apparent hegemony of English, is only one part of the wider problem of neoliberalizing practices and the obsession with measuring everything, including impact and productivity. $\mathrm{He}$ also says, very convincingly, that the idea of a shared (universal) geographical tradition is a fiction. We should be careful, he says, of clearly identifying attempts to cast "other" (national) geographies as some sort of parallel narrative to something bigger and more important taking place elsewhere.

These three interventions raise the question of how we write, for whom and in what style. They also raise the question of how we communicate such writing in public venues and within our diverse academic communities if we really want to foster new dialogues, including viva voce. During the event - while writing about "the event"! - Strohmayer read, at great pace and with characteristic gusto, a paper written to be read carefully, not spoken. Likewise, several other papers were read not by their authors who could not be present, but by kind others. In a forum of native speakers, this would be standard practice, and a familiar enough form to follow. But to an audience of non-native speakers, such performances raise different questions about how we can facilitate knowledge production and circulation, and build welcoming spaces for our work, including for emerging scholars. Furthermore, do such word-rich, picture-poor modes of presentation allow for the kind of wide engagement across highly normed modes of engagement that we claim to be seeking? Are we really creating new spaces for innovative engagement if we adopt hegemonic formats without revisiting them for new diverse audiences? Before I hear my dear colleagues hissing at me (in the language of their choice), let me say that this isn't in any way a specific attack after an unusual and joyful event: at practically every geographical conference where erudite talkers have limited time to present complex thoughts, the temptations of density overtake legibility. How could we do this better? Translating concepts on slides, as is often done in multilingual settings? But translation, as many of the authors here note, and as I have written elsewhere (Fall, 
2013), is a complex balancing act, about more than words. Perhaps the journal Geographical Helvetica will become the much-needed new space for debating concepts across traditions, and in so doing might also question the modes of presentation and publication adopted.

Edited by: B. Korf

Reviewed by: two anonymous referees

\section{References}

Fall, J. J.: Writing (the Other), in: The SAGE Handbook of Progress in Human Geography, edited by: Lee, R., Castree, N., Kitchin, R., Lawson, V., Paasi, A., Radcliffe, S., and Withers, C., SAGE, in press, 2013. 